\title{
Antichronic Gastric Ulcer Effect of Zinc-Baicalin Complex on the Acetic Acid-Induced Chronic Gastric Ulcer Rat Model
}

\author{
Hui Yang $\mathbb{D}^{1},{ }^{1}$ Yi Lu, ${ }^{2}$ Xiao-Feng Zeng, ${ }^{3}$ Ling Li, ${ }^{1}$ Rong-Ping Zhang, ${ }^{1}$ Zhong-Kun Ren $\mathbb{D}^{2}$ \\ and $\mathrm{Xu}$ Liu ${ }^{1}{ }^{1}$ \\ ${ }^{1}$ Biomedical Engineering Center, Kunming Medical University, Kunming 650500, China \\ ${ }^{2}$ Neurosurgery, The 1st Affiliated Hospital of Kunming Medical University, Kunming 650032, China \\ ${ }^{3}$ School of Forensic Medicine, Kunming Medical University, Kunming 650500, China
}

Correspondence should be addressed to Zhong-Kun Ren; renzhongkunbio@163.com and Xu Liu; liuxu1956@163.com

Received 28 February 2018; Revised 11 August 2018; Accepted 2 September 2018; Published 28 October 2018

Academic Editor: Haruhiko Sugimura Copyright (c) 2018 Hui Yang et al. This is an open access article distributed under the Creative Commons Attribution License, which
permits unrestricted use, distribution, and reproduction in any medium, provided the original work is properly cited.

\begin{abstract}
Background. Baicalin (BA) has been shown to have anti-inflammatory and antioxidant activity. Zinc is a nutrient element. Objective. This study is aimed at investigating the antichronic gastric ulcer activity of $\mathrm{Zn}$-Baicalin complex (BA-Zn) and its related mechanisms in an acetic acid-induced gastric ulcer rat model. Results. The severely ulcerated gastric mucosa of model rats had lower GSH-Px $(52.21 \pm 7.13)$ and SOD $(7.03 \pm 0.10)$ activity, and higher MDA $(2.39 \pm 0.03)$ content compared to sham rats. BA-Zn reduced the gastric ulcer index in a dose-dependent manner, significantly increased SOD activity and GSH-Px level, and reduced the MDA content and IL- 8 and TNF- $\alpha$ levels in the gastric mucosa. BA-Zn (6.5 and $13 \mathrm{mg} / \mathrm{kg}$ ) exerted a greater antiulcerogenic effect than both BA and zinc-gluconate, leading to a reduced ulcer index $(18.43 \pm 1.11,15.00 \pm 1.44)$, decreased MDA content $(1.33 \pm 0.07,0.63 \pm 0.01)$, and increased SOD activity $(17.62 \pm 0.11,20.12 \pm 0.32)$ and GSH-Px levels $(102.12 \pm 9.11$, $120.25 \pm 9.07)$. In addition, our results from Western blot suggested that BA-Zn $(6.5$ and $13 \mathrm{mg} / \mathrm{kg})$ has a greater antiulcerogenic effect than both BA and zinc-gluconate. Conclusion. The BA-Zn complex possesses greater antichronic gastric ulcer properties compared to BA and zinc-gluconate due to its ability of oxidation resistance and anti-inflammatory effects.
\end{abstract}

\section{Introduction}

Peptic ulcers create a serious disease state in humans, are common worldwide, and have an increasing incidence rate. Gastric ulceration often increases the level of gastric acid secretion, can damage the gastric mucosal barrier, and penetrates the mucus layer $[1,2]$. An ulcer model induced by acetic acid in rats resembles human chronic ulcers in both pathological features and healing process. Therefore, this model is more promising and useful for researchers to explore gastric ulcer. The pathogenesis of gastric ulcers is complex due to multifactorial and complex interaction between protective and destructive factors. Nonsteroidal anti-inflammatory drugs (NSAIDs) are the most commonly recommended medication and are comprehensively used to decrease clinical cases of pain and inflammation [3]. However, these drugs are known to induce intestinal ulcerations and hinder ulcer healing [4]. Traditional medicinal herbs and plants offer great promise in the treatment of many diseases and are an important source of new chemical substances with potential therapeutic effects to treat several diseases.

Chemical moieties isolated from plants have a long history of beneficial effects for treating ulcers. Baicalin (BA) is a flavonoid compound extracted and purified from the Chinese medicinal herb Scutellaria baicalensis Georgi, which has been demonstrated to have antiulcer, antipyretic, anti-inflammatory, analgesic, anticancer, antioxidant, and wound healing properties [5-10]. Zinc is essential for the maintenance of human cell functions. Moreover, it is reported that zinc can promote the healing of small intestinal mucosal damage. Zinc loss could significantly impair wound healing [11]. Zinc is also a free radical scavenger and anti-inflammatory agent, which can halt the progression of gastrointestinal disease and interrupt the associated inflammatory processes. Zinc 
complexes have always exerted potent antiulcer activity. Zinc-carnosine is a common antiulcer drug used in the treatment of gastric ulcers in Japan [12]. However, there is little research about the antichronic gastric ulcer ability of BA$\mathrm{Zn}$, and its related mechanism is still unclear.

It was reported that reactive oxygen species (ROS) played an important role in digestive disorders $[13,14]$. In addition, oxygen free radical production and lipid peroxidation play an essential function in the development of gastric ulceration $[15,16]$. Moreover, alterations to the antioxidant defense system in ulcerative disorders suggest a vital role for free radicals in ulcerations induced by acetic acid. Inflammatory cytokines such as IL-8 can also influence gastric ulcer healing $[17,18]$. Thus, inflammatory cytokines are regarded as indicators of gastric ulcers.

In this study, we investigated whether the BA-Zn complex possesses antiulcer activity in a rat model of acetic acid-induced chronic gastric ulcer through free radical scavenging and anti-inflammatory activity.

\section{Materials and Methods}

2.1. Chemicals and Reagents. Baicalin (BA, Mw: 464.38) was purchased from Wanfang Chemical Company (Yunnan, China). The zinc complex of baicalin (BA- $\mathrm{Zn}, \mathrm{Zn}\left(\mathrm{C}_{21} \mathrm{H}_{17} \mathrm{O}_{11}\right)\left(\mathrm{CH}_{3-}\right.$ $\mathrm{COO}) \cdot 3.5 \mathrm{H}_{2} \mathrm{O}, \mathrm{Mw}$ : 632) was synthesized by the College of Pharmacy of Kunming Medical University. The LD50 of the zinc-baicalin (BA-Zn) complex is $4.76 \mathrm{~g} / \mathrm{kg} \cdot \mathrm{bw}$, and the ED50 is $1.042 \mathrm{mg} / \mathrm{kg}$. IL-8, TNF- $\alpha$, SOD, GSH-Px, and MDA kits were purchased from Nanjing Jiancheng Research Institute (Nanjing, China).

2.2. Preparation of $B A-Z n .500 \mathrm{ml}$ of water was added to $50 \mathrm{~g}$ of BA in a beaker, stirring constantly, and making this into a suspension liquid, heating to $55^{\circ} \mathrm{C}$ at $\mathrm{pH} 6.5-7.0$, then adding a zinc acetate-saturated solution, and mixing fully. This was then cooled to room temperature, and filtered for red precipitation. This was then washed with $75 \%$ ethanol and $\mathrm{ddH}_{2} \mathrm{O}_{2}$, respectively, and finally drying these precipitation at $60^{\circ} \mathrm{C}$.

2.3. Animals. Healthy male Sprague-Dawley rats, 7 weeks old and weighing 180-200 g, were from the experimental animal center of Kunming Medical College (certificate number SCXK2005-0008). The Animal Ethics Committee agreement number is KMMU2015011. The animals were housed on a pathogen-free environment with a constant $12 \mathrm{~h}$ light/12 h dark cycle in a temperature-controlled central facility (18$22^{\circ} \mathrm{C}$ ) with free access to normal chow and tap water for a week. All procedures were in accordance with the Animal Ethics Committee of Kunming Medical University and the Guide for the Care and Use of Laboratory Animals.

2.4. Experimental Protocol for Ulceration and Healing. Animals were divided randomly into eight experimental groups with 10 animals in each group: the sham group (water vehicle, p.o. (per os)), model group (chronic gastric ulcers), BAZn groups (3.25, 6.5, and $13 \mathrm{mg} / \mathrm{kg} \mathrm{BA}-\mathrm{Zn}, \mathrm{p.o.})$, BA group (4.6 mg/kg BA, p.o.), zinc-gluconate group $(9.32 \mathrm{mg} / \mathrm{kg}$, p.o.), and omeprazole group ( $4.0 \mathrm{mg} / \mathrm{kg}$ omeprazole, p.o.).
Chronic gastric ulcers were induced with acetic acid according to the method of Okabe et al. [19]. Briefly, the rats were anesthetized with sodium pentobarbital $(30 \mathrm{mg} / \mathrm{kg}$, respectively, i.p. (intraperitoneal injection)), and then the abdomen was opened, and the stomach exposed. A solution of $80 \%$ acetic acid (v/v, $0.5 \mathrm{ml})$ was instilled into a cylinder $(5 \mathrm{~mm}$ of diameter) that was applied to the serosal surface of the stomach and, after $1 \mathrm{~min}$, was removed by aspiration; the area of contact was washed with sterile saline. Forty-eight hours after ulcer induction, the rats were orally treated with vehicle (sham: water, $1 \mathrm{mg} / \mathrm{kg})$, BA $(4.6 \mathrm{mg} / \mathrm{kg})$, zinc-gluconate $(9.32 \mathrm{mg} / \mathrm{kg})$, omeprazole $(4.0 \mathrm{mg} / \mathrm{kg})$, and $\mathrm{BA}-\mathrm{Zn}(3.25$, $6.5,13 \mathrm{mg} / \mathrm{kg}$ ) once a day for 7 days. On the day following the last treatment, all animals were alive. Then, the animals were euthanatized by an overdose of pentobarbital sodium $(150 \mathrm{mg} / \mathrm{kg}$, i.p.), and the stomachs were removed and opened for the measurement of the ulcer area $\left(\mathrm{mm}^{2}\right)$ as length $(\mathrm{mm}) \times$ width $(\mathrm{mm})$. The gastric ulcer tissue was used for the following tests.

2.5. Histological Preparation. A sample obtained from the middle of the gastric lesion was processed according to the conventional procedure and stained with hematoxylineosin. The stomachs were removed, filled with $5 \mathrm{ml}$ of $10 \%$ formalin and allowed to stand for $5 \mathrm{~min}$; then, these were cut open along the greater curvature. The longitudinal and abscissal lengths of the upper, opened part of the ulcer were measured with a micrometer that was attached to a stereoscopic microscope, and the product of both lengths $\left(\mathrm{mm}^{2}\right)$ is expressed in terms of the ulcer index (Table 1). After the ulcer size was measured, the stomach tissue was again immersed in $10 \%$ formalin for $24 \mathrm{~h}$. The formalin-fixed tissues were then cut so that a small amount of the normal tissue surrounding the ulcer remained.

2.6. Hematoxylin and Eosin Staining. The stomach tissues were immediately fixed in $4 \%$ paraformaldehyde for $48 \mathrm{~h}$ at $4^{\circ} \mathrm{C}$. Paraffin sections $(5 \mu \mathrm{m})$ were prepared and then stained with hematoxylin and eosin (HE) according to standard procedures. Tissue were observed and microphotographed under a light microscope.

2.7. Detection of SOD Activity, GSH-Px, MDA, IL-8, and $T N F-\alpha$ Levels. Gastric tissue from the ulcerated portion of the stomach was excised, washed with distilled water, chopped, and homogenized at $3000 \mathrm{rpm}$ in chilled Tris buffer $(10 \mathrm{mM}, \mathrm{pH} 7.4)$ at a concentration of $10 \% \mathrm{w} / \mathrm{v}$. Then, the homogenate was centrifuged at $9000 \times \mathrm{g}$ at $4^{\circ} \mathrm{C}$ for $20 \mathrm{~min}$ and the supernatants were used for the determination of superoxide dismutase (SOD), methylenedioxyamphetamine (MDA), and GSH-Px (glutathione peroxidase) contents, as well as IL- 8 and TNF- $\alpha$ expression levels by using the following detection kits purchased from Nanjing Jiancheng Biotechnology Co. Ltd.: a superoxide dismutase (SOD) assay kit (WST-1 method) (no. 20160914); glutathione peroxidase (GSH-Px) assay kit (colorimetric method) (no. 20160115); malondialdehyde (MDA) assay kit (TBA method) (no. 20161130); interleukin-8 assay kit (no. 20160815); and tumor necrosis factor- $\alpha$ assay kit (no. 20160703). The changes in 
TABLE 1: Effect of BA-Zn on oxidant stress in rat mucosa induced by acetic acid.

\begin{tabular}{|c|c|c|c|c|c|}
\hline Group & $(\mathrm{mg} / \mathrm{kg})$ & Ulcer index $\left(\mathrm{mm}^{2}\right)$ & $\mathrm{SOD}(\mathrm{U} / \mathrm{mg})$ & $\operatorname{MDA}(\mu \mathrm{mol} / \mathrm{l})$ & GSH-Px (U/l) \\
\hline Sham & - & $0 \pm 0^{* * *}$ & $22.09 \pm 0.09^{* * *}$ & $0.91 \pm 0.06^{* * *}$ & $136.09 \pm 9.09^{* * *}$ \\
\hline Model & - & $28.35 \pm 3.27$ & $7.03 \pm 0.10$ & $2.39 \pm 0.03$ & $52.21 \pm 7.13$ \\
\hline \multirow[t]{2}{*}{$\mathrm{BA}$} & 4.6 & $24.38 \pm 2.30^{*}$ & $12.09 \pm 0.13^{* *}$ & $3.54 \pm 0.04^{*}$ & $85.07 \pm 7.11^{* *}$ \\
\hline & 3.25 & $24.94 \pm 2.00^{*}$ & $6.75 \pm 0.06$ & $1.75 \pm 0.07^{* *}$ & $55.11 \pm 6.06$ \\
\hline \multirow[t]{2}{*}{$\mathrm{BA}-\mathrm{Zn}$} & 6.5 & $18.43 \pm 1.11^{* * *}$ & $17.62 \pm 0.11^{* * *}$ & $1.33 \pm 0.07^{* * *}$ & $102.12 \pm 9.11^{* * *}$ \\
\hline & 13 & $15.00 \pm 1.44^{* * *}$ & $20.12 \pm 0.32^{* * *}$ & $0.63 \pm 0.01^{* * *}$ & $120.25 \pm 9.07^{* * *}$ \\
\hline Zinc-gluconate & 9.32 & $23.71 \pm 2.00^{*}$ & $9.07 \pm 0.33^{*}$ & $2.00 \pm 0.12$ & $80.35 \pm 6.77^{*}$ \\
\hline Omeprazole & 4 & $15.35 \pm 1.22^{* * *}$ & $19.32 \pm 0.09^{* * *}$ & $1.00 \pm 0.11^{* * *}$ & $107.12 \pm 9.05^{* * *}$ \\
\hline
\end{tabular}

${ }^{*} P<0.05,{ }^{* *} P<0.01$, and ${ }^{* * *} P<0.001$, vs. the model group.

absorbance were determined using a spectrophotometer; the results are expressed as $\mathrm{U} / \mathrm{l}$ and $\mu \mathrm{mol} / \mathrm{l}$ for GSH-Px and MDA, U/mg protein for SOD activity, and $\mathrm{ng} / \mathrm{ml}$ for IL-8 and TNF- $\alpha$ levels.

2.8. Western Blot Analysis. Western blot analysis was used for the protein expression levels of SOD1, TNF- $\alpha$, and IL-8. Total proteins of tissues were extracted with lysis buffer (Beyotime, China). The insoluble protein lysate was removed by centrifugation at $10,000 \times \mathrm{g}$ for $10 \mathrm{~min}$ at $4^{\circ} \mathrm{C}$. Total proteins were separated by $10 \%$ sodium dodecyl sulfate-polyacrylamide gel electrophoresis (SDS-PAGE), followed by blocking in 5\% skim milk on a PVDF membrane. The membranes were hybridized with primary antibodies (Proteintech, USA) for $2 \mathrm{~h}$ at $4^{\circ} \mathrm{C}$ and then with secondary antibodies (Proteintech, USA) for $2 \mathrm{~h}$ at room temperature. The bands were developed using an enhanced chemiluminescence (ECL) detection system (EMD Millipore, USA) for horseradish peroxidase (HRP). The relative amounts of the various proteins were analyzed. $\beta$-Actin was used as a loading control. The results were quantified using ImageJ software.

2.9. Statistical Analysis. All the results were expressed as mean \pm SD. Statistical comparisons were made between drug-treated groups and acetic acid groups. The data was statistically analyzed by one-way analysis of variance (ANOVA) (Tukey's post hoc test) using GraphPad Prism software version 5.0a (GraphPad Software Inc., California, USA). $P<0.05$ was considered to be statistically significant.

\section{Results}

3.1. BA-Zn Protects against Acetic Acid-Induced Gastric Lesions. The molecular formula of $\mathrm{BA}-\mathrm{Zn}$ is $\mathrm{Zn}\left(\mathrm{C}_{21} \mathrm{H}_{17} \mathrm{O}_{11}\right)\left(\mathrm{CH}_{3} \mathrm{COO}\right) \cdot 3.5 \mathrm{H}_{2} \mathrm{O}$, and it has a molecular weight of $632 \mathrm{~g} / \mathrm{mol}$ (Figure 1). The macroscopic appearance of the gastric tissue is shown in Figure 2. Rats treated with only water (Figure 2(a)) showed a normal glandular stomach. Figure 2(b) shows the deep ulceration and severe edematous changes in the gastric mucosa of the model group that was induced with $80 \%$ acetic acid and treated with water daily. By contrast, rats treated with BA-Zn $(3.25,6.5$, or $13 \mathrm{mg}$ / $\mathrm{kg}$ ) or BA, zinc-gluconate, or omeprazole showed less severe ulceration and less edema in the gastric mucosa induced by $80 \%$ acetic acid (Figures $2(\mathrm{c})-2(\mathrm{~h})$ ).

As shown in Figure 3(a), the microscopic histological appearance of the gastric tissue and the normal gastric epithelium was observed in the sham group. The application of acetic acid induced the disruption of the superficial region of the gastric gland with loss of epithelial cells, as well as pronounced edema of the submucosa and degradation of the mucosa in the model group (Figure 3(b)).

BA-Zn $(3.25,6.5$, and $13 \mathrm{mg} / \mathrm{kg}$ ) and omeprazole markedly reduced the severity of gastric ulcers (swelling, destruction, and extensive destruction on the surface of the epithelium) and promoted marginal regeneration of the epithelium compared to the model group (Figures 3(c)-3(e) and $3(\mathrm{~h}))$. In the BA $(4.6 \mathrm{mg} / \mathrm{kg})$ and zinc-gluconate- $(9.32 \mathrm{mg} /$ $\mathrm{kg}$ ) treated groups, the severity of the gastric ulcers was also inhibited (Figures 3(f) and 3(g)).

In all animals from all the groups that survived, the longitudinal and abscissal lengths of the upper, opened part of the ulcer were measured with a micrometer that was attached to a stereoscopic microscope, and the product of both lengths $\left(\mathrm{mm}^{2}\right)$ was expressed in terms of the ulcer index. As shown in Table 1, the sham group showed no ulcer index, and administration of $\mathrm{BA}-\mathrm{Zn}$ at doses of 3.25, 6.5 , and $13 \mathrm{mg} / \mathrm{kg}$ decreased the gastric ulcer index to $24.94 \pm 2.00(P<0.05), 18.43 \pm 1.11(P<0.001)$, and $15.00 \pm$ $1.44 \mathrm{~mm}^{2}(P<0.001)(12.0 \%, 35.0 \%$, and $47.1 \%$ protection, respectively), compared to the ulcer index of the model group which was $28.35 \pm 3.27 \mathrm{~mm}^{2}$. BA $(4.6 \mathrm{mg} / \mathrm{kg})$ reduced the gastric ulcer index to $24.38 \pm 2.30(P<0.05)$ compared to that of the model group. Zinc-gluconate $(9.32 \mathrm{mg} / \mathrm{kg})$ also reduced the gastric ulcer index to $23.71 \pm 2.00 \quad(P<0.05)$ compared to that of the model group. Moreover, zincgluconate had a higher gastric ulcer index than the BA-Zn group (6.5 and $13 \mathrm{mg} / \mathrm{kg}, P<0.001$, respectively). It indicated that BA-Zn $(6.5$ and $13 \mathrm{mg} / \mathrm{kg})$ has a stronger healing effect than zinc-gluconate. Omeprazole $(4.0 \mathrm{mg} / \mathrm{kg})$, the positive control drug, demonstrated a potency for reducing the gastric ulcer index $\left(15.35 \pm 1.22 \mathrm{~mm}^{2} ; P<0.001\right.$ compared to the model group). BA- Zn (13 mg/kg) showed the best potency for reducing the gastric ulcer index, which was the same as omeprazole. 


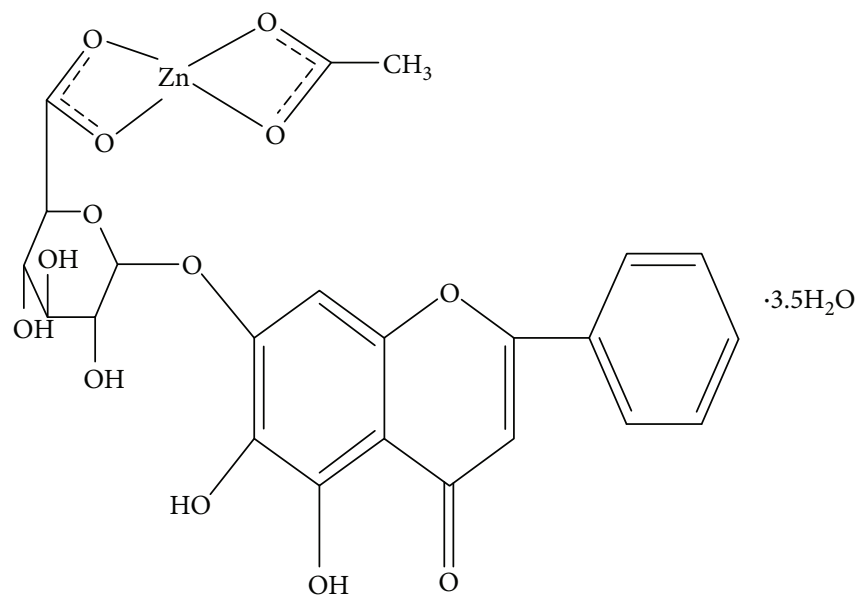

FIGURE 1: Structural formula of BA-Zn.

3.2. BA-Zn Suppressed Oxidative Stress in Acetic AcidInduced Gastric Tissue of Rats. Increased oxidative stress was shown in the ulcerated gastric mucosa of the model group, and this group also had significantly decreased SOD and GSH-Px activities and an increased level of lipid peroxidation (MDA) content compared to those of the sham group $(P<0.001)$.

As shown in Table 1, SOD activity in the mucosa of the model group was significantly lower $(7.03 \pm 0.10 \mathrm{U} / \mathrm{mg}$ protein) than in the sham group $(22.09 \pm 0.09 \mathrm{U} / \mathrm{mg}$ protein; $P<0.001)$. BA-Zn treatment at 6.5 and $13 \mathrm{mg} / \mathrm{kg}$ significantly increased the SOD activity to $17.62 \pm 0.11$ and $20.12 \pm 0.32 \mathrm{U} /$ mg protein $(P<0.001$ and $P<0.001)$, respectively, compared to that of the model group $(7.03 \pm 0.10 \mathrm{U} / \mathrm{mg}$ protein). Moreover, the administration of 6.5 and $13 \mathrm{mg} / \mathrm{kg} \mathrm{BA}-\mathrm{Zn}$ led to higher SOD activity than did the administration of BA $(17.62 \pm 0.11$ and $20.12 \pm 0.32$ vs. $12.09 \pm 0.13 \mathrm{U} / \mathrm{mg}$ protein; $P<0.05$ and $P<0.01$ ), and these also markedly increased SOD activity than that of the zinc-gluconate group $(9.07 \pm$ $0.33 \mathrm{U} / \mathrm{mg}$ protein; $P<0.001)$. It indicated that $\mathrm{BA}-\mathrm{Zn}$ has a stronger antioxidative effect than BA and zinc-gluconate. Zinc-gluconate $(9.32 \mathrm{mg} / \mathrm{kg})$ significantly increased SOD activity to $9.07 \pm 0.33 \mathrm{U} / \mathrm{mg}$ protein $(P<0.05)$ compared to that of the model group $(7.03 \pm 0.10 \mathrm{U} / \mathrm{mg}$ protein). Omeprazole $(4.0 \mathrm{mg} / \mathrm{kg})$ demonstrated an increase in SOD activity $(19.32 \pm 0.09 \mathrm{U} / \mathrm{mg}$ protein; $P<0.001$, compared to that of the model group).

GSH-Px levels in the gastric mucosa of the model group were significantly lower than in the sham group (52.21 \pm 7.13 vs. $136.09 \pm 9.09 \mathrm{U} / 1 ; P<0.001)$. Administration of 6.5 and $13 \mathrm{mg} / \mathrm{kg}$ BA-Zn significantly increased the GSH-Px level in a dose-dependent manner $(P<0.001$ and $P<0.001$, respectively, compared to that of the model group). Moreover, the administration of 6.5 and $13 \mathrm{mg} / \mathrm{kg} \mathrm{BA}-\mathrm{Zn}$ led to increased GSH-Px activity compared to that of the BA group $(102.12 \pm 9.11$ and $120.25 \pm 9.07$ vs. $85.07 \pm 7.11 \mathrm{U} / 1 ; P<0.05)$, and the administration of 6.5 and $13 \mathrm{mg} / \mathrm{kg}$ BA-Zn also markedly increased GSH-Px activity compared to that of the zinc-gluconate group $(80.35 \pm 6.77 \mathrm{U} / \mathrm{l} ; P<0.001)$. It indicated that BA-Zn has a stronger antioxidative effect than BA and zinc-gluconate. Zinc-gluconate $(9.32 \mathrm{mg} / \mathrm{kg})$ significantly increased GSH-Px activity to $80.35 \pm 6.77 \mathrm{U} / \mathrm{l}$ $(P<0.05)$ compared to that of the model group $(52.21 \pm$ $7.13 \mathrm{U} / \mathrm{l})$. Omeprazole $(4.0 \mathrm{mg} / \mathrm{kg})$ demonstrated an increase in GSH-Px activity $(107.12 \pm 9.05 \mathrm{U} / \mathrm{l} ; P<0.001$ compared to that of the model group).

The inhibitory effects of BA- $\mathrm{Zn}$ on lipid peroxidation (MDA) are shown in Table 1. The MDA content in the gastric mucosa of the model group was higher than in the sham group $(2.39 \pm 0.03$ vs. $0.91 \pm 0.06 \mu \mathrm{mol} / \mathrm{l} ; P<0.001)$. Treatment with $3.25,6.5$, and $13 \mathrm{mg} / \mathrm{kg} \mathrm{BA}-\mathrm{Zn}$ significantly decreased the MDA content to $1.75 \pm 0.07,1.33 \pm 0.07$, and $0.63 \pm 0.01 \mu \mathrm{mol} / \mathrm{l} \quad(P<0.01, \quad P<0.001$, and $P<0.001$, respectively, compared to that of the model group). Moreover, the administration of $3.25,6.5$, and $13 \mathrm{mg} / \mathrm{kg} \mathrm{BA}-\mathrm{Zn}$ led to lower MDA activity than BA $(1.75 \pm 0.07,1.33 \pm$ 0.07 , and $0.63 \pm 9.01$ vs. $3.54 \pm 0.04 \mu \mathrm{mol} / \mathrm{l} ; P<0.05)$ and the zinc-gluconate group $(2.00 \pm 0.12 \mu \mathrm{mol} / \mathrm{l} ; \quad P<0.001)$, indicating that BA-Zn had a stronger antioxidative effect than BA and zinc-gluconate. Zinc-gluconate $(9.32 \mathrm{mg} / \mathrm{kg})$ showed a decrease in MDA content $(2.00 \pm 0.12 \mu \mathrm{mol} / \mathrm{l}$; $P<0.05$ compared to that the model group). Omeprazole $(4.0 \mathrm{mg} / \mathrm{kg})$ also demonstrated a decrease in MDA content $(1.00 \pm 0.11 \mu \mathrm{mol} / 1 ; P<0.001$ compared to that of the model group).

3.3. Effect of BA-Zn on the Concentration of TNF- $\alpha$ and IL-8. As shown in Table 2, the level of TNF- $\alpha$ in the model group was significantly higher than in the sham group $(2.73 \pm 0.10$ vs. $0.72 \pm 0.09 \mathrm{ng} / \mathrm{ml} ; P<0.001)$. The administration of 3.25 , 6.5 , and $13 \mathrm{mg} / \mathrm{kg} \mathrm{BA}-\mathrm{Zn}$ significantly decreased the TNF- $\alpha$ concentration in a dose-dependent manner $(1.95 \pm 0.06$, $1.62 \pm 0.11$, and $1.12 \pm 0.32 ; P<0.05, P<0.001$, and $P<$ 0.001 , respectively, compared to that of the model group). Zinc-gluconate $(9.32 \mathrm{mg} / \mathrm{kg})$ demonstrated a decreased TNF$\alpha$ level $(2.00 \pm 0.11 \mathrm{ng} / \mathrm{ml} ; P<0.05$ compared to that of the model group). Administration of 6.5 and $13 \mathrm{mg} / \mathrm{kg} \mathrm{BA-Zn} \mathrm{sig-}$ nificantly decreased the TNF- $\alpha$ concentration compared to that of the zinc-gluconate group $(2.00 \pm 0.11 \mathrm{ng} / \mathrm{ml} ; P<0.001)$. Omeprazole $(4.0 \mathrm{mg} / \mathrm{kg})$ demonstrated a decreased TNF- $\alpha$ concentration $(1.32 \pm 0.09 \mathrm{ng} / \mathrm{ml} ; P<0.001$ compared to that of the model group). 


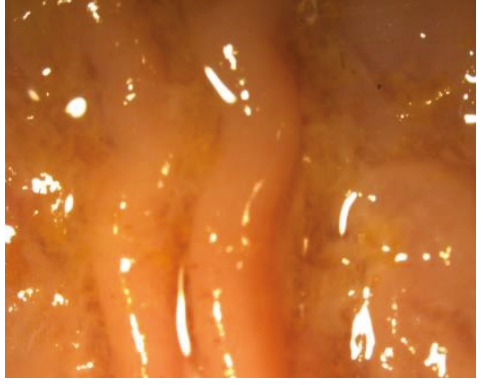

(a)

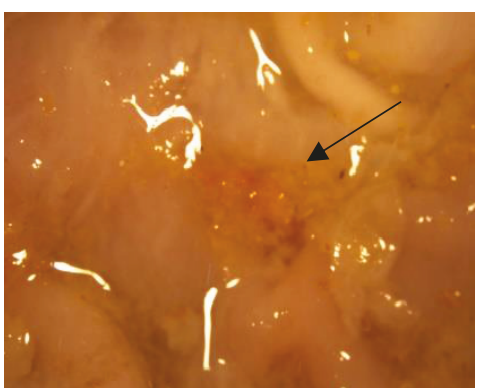

(d)

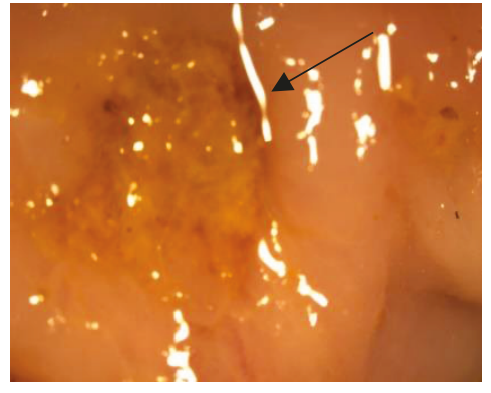

(b)

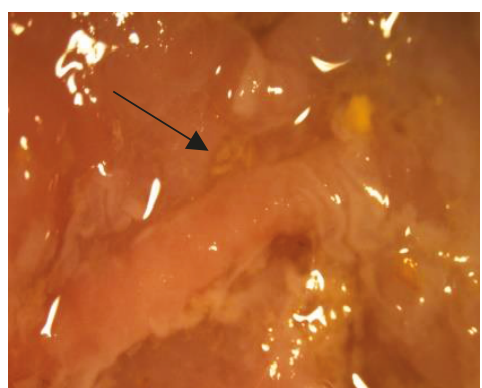

(e)

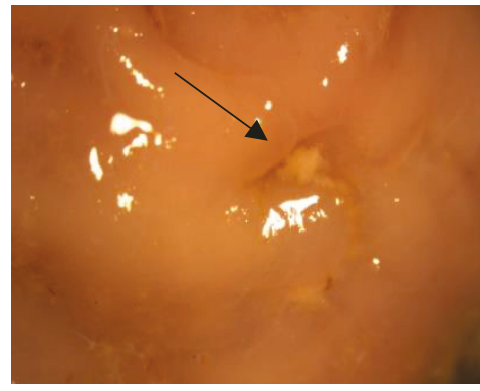

(c)

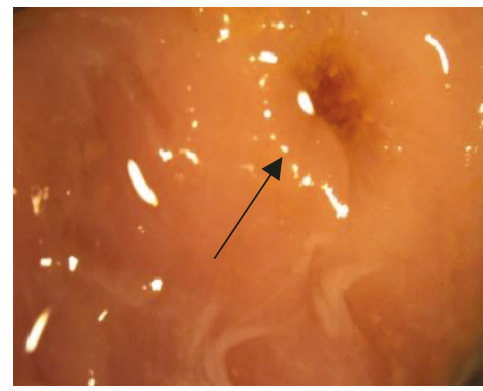

(f)

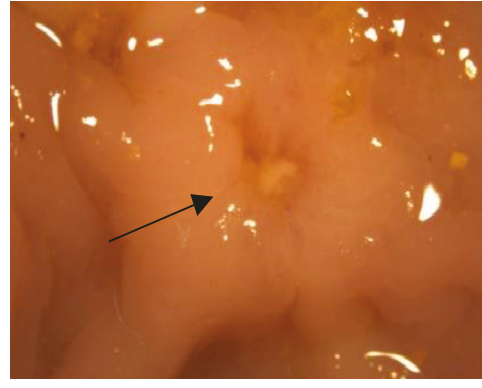

(g)

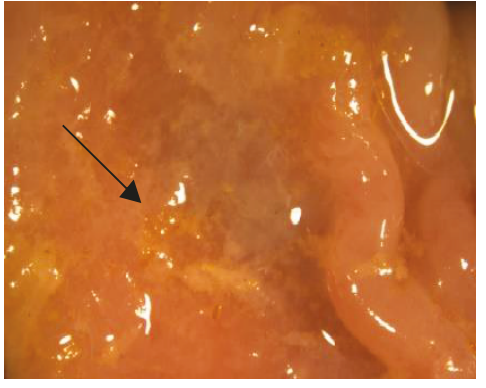

(h)

Figure 2: Appearances of acetic acid-induced gastric ulcers in different groups: (a) the sham group treated daily with water, (b) an ulceration from the model group induced by acetic acid, (c-e) an ulceration from the BA-Zn group induced by acetic acid and treated daily with BA-Zn $(3.25,6.5$, and $13 \mathrm{mg} / \mathrm{kg}$, p.o.), (f) an ulceration from the BA group induced by acetic acid and treated daily with BA (4.6 mg/kg, p.o.), (g) an ulceration from the zinc-gluconate group induced by acetic acid and treated daily with zinc-gluconate $(9.32 \mathrm{mg} / \mathrm{kg}$, p.o.), and (h) an ulceration from the omeprazole group induced by acetic acid and treated daily with omeprazole $(4.0 \mathrm{mg} / \mathrm{kg}$, p.o.). Black arrows indicate ulcer location.

The level of IL-8 in the model group was significantly higher than in the sham group $(0.69 \pm 0.03$ vs. $0.21 \pm$ $0.06 \mathrm{ng} / \mathrm{ml} ; \quad P<0.01)$. Administration of $3.25,6.5$, and $13 \mathrm{mg} / \mathrm{kg}$ BA-Zn significantly decreased the IL-8 level in a dose-dependent manner $(0.36 \pm 0.07,0.33 \pm 0.07$, and $0.29 \pm$ $0.01 ; P<0.01, P<0.01$, and $P<0.001$, respectively, compared to that of the model group). Zinc-gluconate $(9.32 \mathrm{mg} /$ $\mathrm{kg})$ demonstrated a decreased IL-8 level $(0.60 \pm 0.01 \mathrm{ng} / \mathrm{ml}$; $P<0.05$ compared to that of the model group). Administration of $3.25,6.5$, and $13 \mathrm{mg} / \mathrm{kg} \mathrm{BA}-\mathrm{Zn}$ significantly decreased the IL-8 concentration compared to that of the zincgluconate group $(0.60 \pm 0.01 \mathrm{ng} / \mathrm{ml} ; P<0.001)$. Omeprazole $(4.0 \mathrm{mg} / \mathrm{kg})$ also demonstrated a decreased IL-8 level $(0.45 \pm$ $0.01 \mathrm{ng} / \mathrm{ml} ; P<0.05$ compared to the model group).

To further demonstrate the effect of BA-Zn on the concentration of SOD, TNF- $\alpha$, and IL- 8 in the above groups, Western blot assays were used to detect the expression levels of these proteins. In Figure 4(a) and 4(b), we reveal that BA-Zn treatment significantly increased SOD expression compared to that in the model and zinc-gluconate groups. BA-Zn also significantly decreased the expression of TNF- $\alpha$ and IL- 8 compared to that in the model and zinc-gluconate groups. In summary, the above results indicate that BA- $\mathrm{Zn}$ had better antioxidative and anti-inflammatory effects than both BA and zinc-gluconate.

\section{Discussion}

Gastric ulcer is a common dysfunction of the digestive system, and an increasing number of people worldwide are suffering damage from ulcers. The acetic acid-induced ulcer model resembles human chronic ulcers in both pathological features and aspects of the healing process [20, 21]; thus, it is the most useful model for us to use when investigating gastric ulcers. Previous studies have demonstrated that experimental gastric ulcers have many histological and ultrastructural abnormalities, including a reduced height, marked dilation of gastric glands, and increased connective tissue, that may 


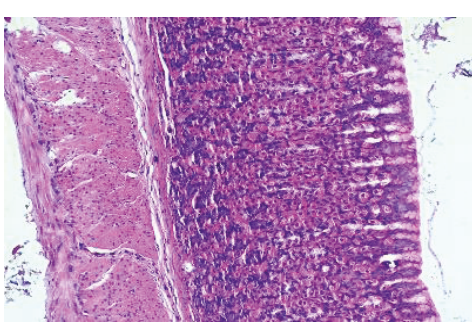

(a)

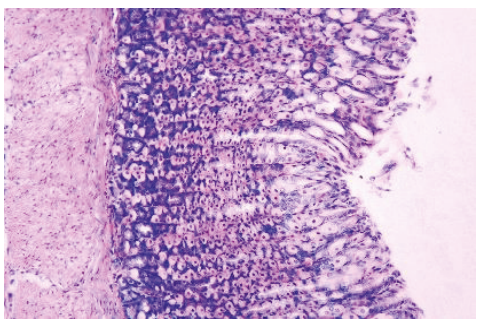

(d)

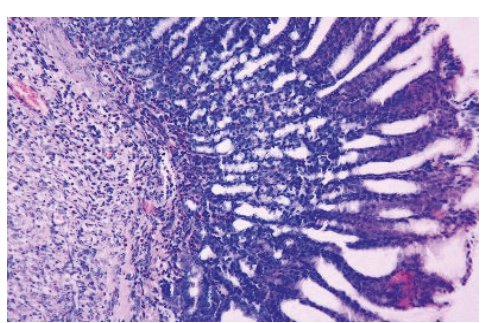

(b)

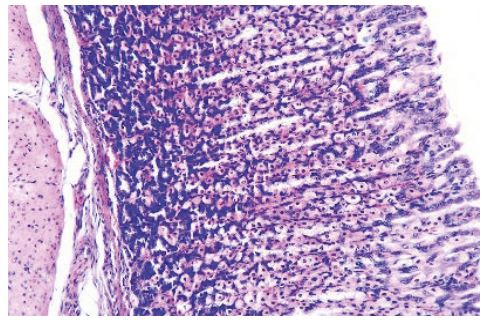

(e)

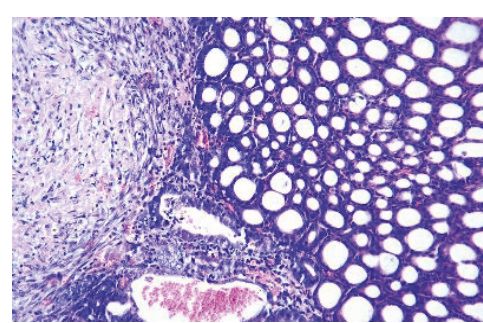

(c)

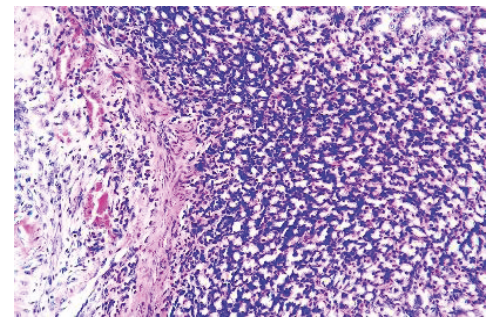

(f)

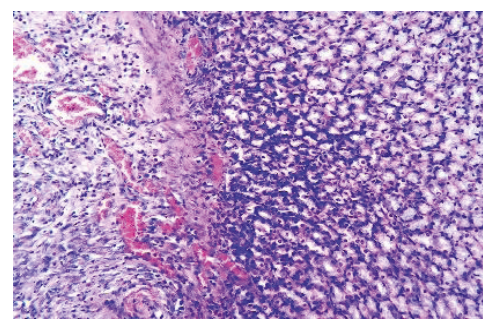

(g)

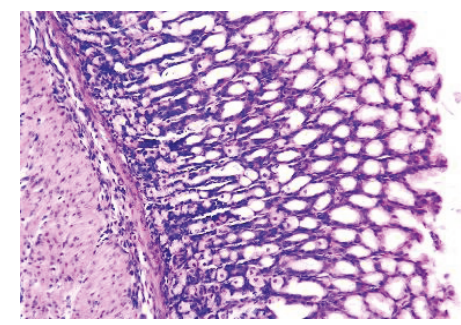

(h)

FIGURE 3: Photomicrographs of acetic acid-induced gastric ulcers from different groups: (a) sham group, (b) HE staining of the model group induced by acetic acid, (c-e) HE staining of the BA-Zn group induced by acetic acid and treated daily with BA-Zn (3.25, 6.5, and $13 \mathrm{mg} / \mathrm{kg}$, p.o.), (f) HE staining of the BA group induced by acetic acid and treated daily with BA ( $4.6 \mathrm{mg} / \mathrm{kg}$, p.o.), (g) HE staining of the zinc-gluconate group induced by acetic acid and treated daily with zinc-gluconate $(9.32 \mathrm{mg} / \mathrm{kg}$, p.o.), and (h) HE staining of the omeprazole group induced by acetic acid and treated daily with omeprazole $(4.0 \mathrm{mg} / \mathrm{kg}$, p.o.). The HE stained slides were visualized under a bright field microscope with 20x magnification.

TABLE 2: Concentration of TNF- $\alpha$ and IL-8 in rat mucosa induced by acetic acid.

\begin{tabular}{lccc}
\hline Group & $(\mathrm{mg} / \mathrm{kg})$ & TNF- $\alpha(\mathrm{ng} / \mathrm{ml})$ & IL-8 $(\mathrm{ng} / \mathrm{ml})$ \\
\hline Sham & - & $0.72 \pm 0.09^{* * *}$ & $0.21 \pm 0.06^{* *}$ \\
Model & - & $2.73 \pm 0.10$ & $0.69 \pm 0.03$ \\
BA & 4.6 & $1.91 \pm 0.13^{*}$ & $0.54 \pm 0.04^{*}$ \\
& 3.25 & $1.95 \pm 0.06^{*}$ & $0.36 \pm 0.07^{* *}$ \\
BA-Zn & 6.5 & $1.62 \pm 0.11^{* * *}$ & $0.33 \pm 0.07^{* *}$ \\
& 13 & $1.12 \pm 0.32^{* * *}$ & $0.29 \pm 0.01^{* * *}$ \\
Zinc-gluconate & 9.32 & $2.00 \pm 0.11^{*}$ & $0.60 \pm 0.01^{*}$ \\
Omeprazole & 4 & $1.32 \pm 0.09^{* * *}$ & $0.45 \pm 0.01^{*}$ \\
\hline
\end{tabular}

${ }^{*} P<0.05,{ }^{* *} P<0.01$, and ${ }^{* * *} P<0.001$, vs. the model group.

interfere with the mucosal defense system and cause ulcer recurrence with some ulcerogenic factors [22, 23].

In recent years, chemical drugs used for the treatment of gastric ulcers have induced many side effects. Recently, newly developed drugs with herbal origins may offer reduced side effects compared with chemical drugs [24].
In folk knowledge, medicinal plants have been used for the treatment of various disorders. More and more medicinal plants with various therapeutic properties, especially for the treatment of gastritis and gastric ulcers, have been identified [25-27]. However, few traditional Chinese medicinal plants for gastric ulcer treatment have been studied. Currently, because of the lack of effective and applicable pharmacological treatments for gastric ulcer, more and more people have focused on traditional medicines. The investigation of the therapeutic functions of traditional medicinal herbs in gastric ulcer offer promising potential.

Scutellaria baicalensis is a popular medicinal herb used in traditional Chinese medicine, and it is used for the treatment of high fevers, ulcers, inflammation, and even cancer. The main bioactive flavonoids in Scutellaria baicalensis include baicalein, baicalin (BA) (baicalein-7-glucuronide), wogonin, wogonoside (wogonin-7-glucuronide), oroxylin A, and oroxylin A-7-glucuronide. Scutellaria baicalensis and its flavones have been studied for their various pharmacological activities, including anti-inflammatory [28], antibacterial [29], neuroprotective [30], anticonvulsant [31], antiviral [32], antitumor [33], and antioxidant [34] activities. BA is the most popular bioactive flavonoid for treating ulcers. However, the 


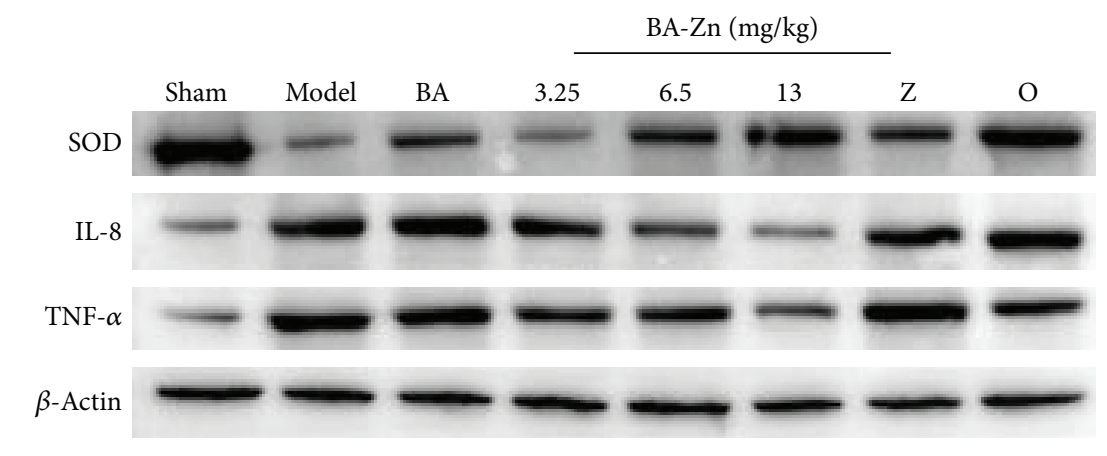

(a)
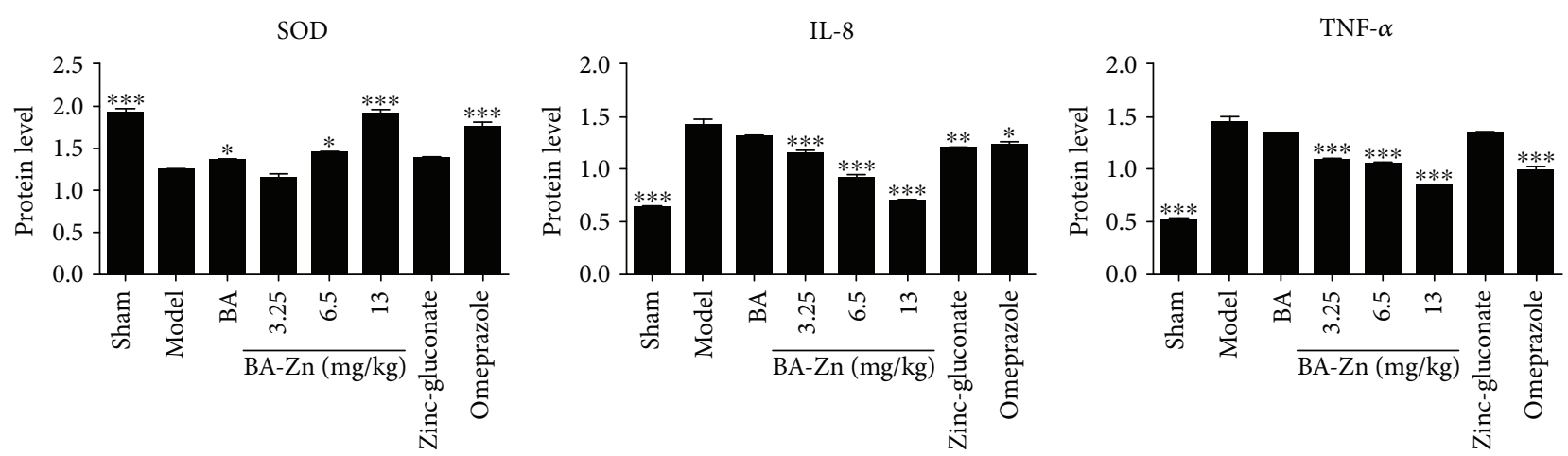

(b)

Figure 4: Western blot analysis of SOD, TNF- $\alpha$, and IL- 8 expression. (a) The protein expression levels of SOD, TNF- $\alpha$, and IL- 8 were analyzed by Western blot analysis. $\beta$-Actin was used as a loading control. (b) Quantification of SOD, TNF- $\alpha$, and IL-8 protein expression levels using ImageJ software. Z: zinc-gluconate, O: omeprazole. ${ }^{*} P<0.05,{ }^{* *} P<0.01$, and ${ }^{* * *} P<0.001$, vs. the model group.

antichronic gastric ulcer effects of BA alone or in complex have not yet been elucidated.

In this paper, we examined the effects of BA-Zn, BA, and zinc-gluconate and related mechanisms on gastric ulcer healing in an acetic acid-induced gastric ulcer rat model. It has been reported that zinc-gluconate has a protective effect on gastric ulcers [35]. Acetic acid induces a state of acute stress in the gastric mucosa, subsequently inducing gastric ulcers. Moreover, acetic acid-induced gastric ulceration leads to chronic oxidative stress with decreased SOD activity and GSH-Px expression levels and increased lipid peroxidation (MDA). It is well known that SOD, GSH-Px, and MDA play important roles in protecting the gastric mucosa against various damaging agents [36, 37]. GSH-Px also plays an important role in protecting against oxidative gastric mucosal injury [38]. MDA is currently regarded as a reliable index of ROS-induced mucosal injury [39]. Therefore, the detection of SOD, GSH-Px, and MDA contents can reflect and indicate the level of oxidative stress. In addition, increased concentrations of TNF- $\alpha$ and IL- 8 were detected in the ulcerated gastric mucosa. BA-Zn (13 mg/kg) significantly accelerated the healing of gastric ulcers, through an increase in SOD and GSH-Px activity and decrease in MDA, IL-8, and TNF$\alpha$ contents. We also detected the levels of SOD, IL- 8 , and TNF- $\alpha$ by Western blot. We found that BA-Zn significantly accelerated ulcer healing by decreasing oxidative stress and attenuating inflammation. In our results, zinc-gluconate also has a protective effect on gastric ulcers, but BA-Zn has much stronger protective and healing abilities in gastric ulcers. On the basis of our data, BA-Zn $(13 \mathrm{mg} / \mathrm{kg})$ has greater antigastric ulcer abilities than either BA or zinc-gluconate.

Collectively, BA-Zn presents important ulcer-healing properties in the model of chronic ulcer induced by acetic acid in rats. Omeprazole is one of the most popular drugs used for the therapeutic control of gastroduodenal ulcers in humans. In our work, BA-Zn also exerted an antiulcerogenic effect similar to that of omeprazole against the development of acetic acid-induced gastric ulcers in rats using antioxidant and anti-inflammatory abilities. Therefore, the BA-Zn complex may become a potential and promising drug for the treatment of human gastroduodenal ulcers. In summary, our study indicates that BA-Zn promotes ulcer healing by decreasing oxidative stress and attenuating inflammation in an acetic acid-induced gastric ulcer rat model. However, additional studies are needed to explore the novel mechanisms of BA-Zn and determine whether other mechanisms are also involved in the antiulcer effects of this complex.

\section{Conclusion}

In conclusion, BA-Zn facilitates the healing of acetic-induced chronic ulcers in rats through its antioxidant and antiinflammatory properties. The results of this study provide a foundation for the clinical application of BA- $\mathrm{Zn}$ in the treatment of gastroduodenal ulcers. 


\section{Data Availability}

The data used to support the findings of this study are available from the corresponding author upon request.

\section{Conflicts of Interest}

The authors declare that there are no conflicts of interest and no financial conflicts regarding the publication of this paper.

\section{Authors' Contributions}

This study was designed by Xu Liu. Experimental work was done by Hui Yang, Zhong-Kun Ren, Yi Lu, Xiao-Feng Zeng, and Ling Li. The first draft of this paper was written by Hui Yang and reviewed by $\mathrm{Xu}$ Liu and Rong-Ping Zhang. Zhong-Kun Ren and Yi Lu reviewed the methodology and results. All authors reviewed and approved the final version.

\section{Acknowledgments}

The present study was supported by the Yunnan Applied Basic Research Projects (Grant no. 2005C00092).

\section{References}

[1] J. L. Goldstein, J. Aisenberg, F. Lanza et al., "A multicenter, randomized, double-blind, active-comparator, placebo-controlled, parallel-group comparison of the incidence of endoscopic gastric and duodenal ulcer rates with valdecoxib or naproxen in healthy subjects aged 65 to 75 years," Clinical Therapeutics, vol. 28, no. 3, pp. 340-351, 2006.

[2] G. H. Heeba, M. K. A. Hassan, and R. S. Amin, "Gastroprotective effect of simvastatin against indomethacin-induced gastric ulcer in rats: role of nitric oxide and prostaglandins," European Journal of Pharmacology, vol. 607, no. 1-3, pp. 188-193, 2009.

[3] P. A. Gladding, M. W. I. Webster, H. B. Farrell, I. S. L. Zeng, R. Park, and N. Ruijne, "The antiplatelet effect of six nonsteroidal anti-inflammatory drugs and their pharmacodynamic interaction with aspirin in healthy volunteers," The American Journal of Cardiology, vol. 101, no. 7, pp. 10601063, 2008.

[4] A. Lanas, M. A. Perez-Aisa, F. Feu et al., "A nationwide study of mortality associated with hospital admission due to severe gastrointestinal events and those associated with nonsteroidal antiinflammatory drug use," The American Journal of Gastroenterology, vol. 100, no. 8, pp. 1685-1693, 2005.

[5] B. Cryer and K. W. Mahaffey, "Gastrointestinal ulcers, role of aspirin, and clinical outcomes: pathobiology, diagnosis, and treatment," Journal of Multidisciplinary Healthcare, vol. 7, pp. 137-146, 2014.

[6] J. Lu, J. S. Wang, and L. Y. Kong, "Anti-inflammatory effects of Huang-Lian-Jie-Du decoction, its two fractions and four typical compounds," Journal of Ethnopharmacology, vol. 134, no. 3, pp. 911-918, 2011.

[7] J. M. Hwang, T. H. Tseng, Y. Y. Tsai et al., "Protective effects of baicalein on tert-butyl hydroperoxide-induced hepatic toxicity in rat hepatocytes," Journal of Biomedical Science, vol. 12, no. 2, pp. 389-397, 2005.

[8] J. Dou, L. Chen, G. Xu et al., "Effects of baicalein on Sendai virus in vivo are linked to serum baicalin and its inhibition of hemagglutinin-neuraminidase," Archives of Virology, vol. 156, no. 5, pp. 793-801, 2011.

[9] M. Y. Yun, J. H. Yang, D. K. Kim et al., "Therapeutic effects of baicalein on atopic dermatitis-like skin lesions of $\mathrm{NC} / \mathrm{Nga}$ mice induced by Dermatophagoides pteronyssinus," International Immunopharmacology, vol. 10, no. 9, pp. 1142-1148, 2010.

[10] J. H. Liu, H. Wann, M. M. Chen et al., "Baicalein significantly protects human retinal pigment epithelium cells against $\mathrm{H}_{2} \mathrm{O}_{2}$-induced oxidative stress by scavenging reactive oxygen species and downregulating the expression of matrix metalloproteinase-9 and vascular endothelial growth factor," Journal of Ocular Pharmacology and Therapeutics, vol. 26, no. 5, pp. 421-429, 2010.

[11] P. D. Zalewski, A. Q. Truong-Tran, D. Grosser, L. Jayaram, C. Murgia, and R. E. Ruffin, "Zinc metabolism in airway epithelium and airway inflammation: basic mechanisms and clinical targets. A review," Pharmacology \& Therapeutics, vol. 105, no. 2, pp. 127-149, 2005.

[12] M. Odashima, M. Otaka, M. Jin et al., "Zinc L-carnosine protects colonic mucosal injury through induction of heat shock protein 72 and suppression of NF- $\kappa \mathrm{B}$ activation," Life Sciences, vol. 79, no. 24, pp. 2245-2250, 2006.

[13] A. Bhattacharyya, R. Chattopadhyay, S. Mitra, and S. E. Crowe, "Oxidative stress: an essential factor in the pathogenesis of gastrointestinal mucosal diseases," Physiological Reviews, vol. 94, no. 2, pp. 329-354, 2014.

[14] L. Chanudom and J. Tangpong, "Anti-inflammation property of Syzygium cumini (L.) Skeels on indomethacin-induced acute gastric ulceration," Gastroenterology Research and Practice, vol. 2015, Article ID 343642, 12 pages, 2015.

[15] L. M. da Silva, A. Allemand, D. A. G. B. Mendes et al., "Ethanolic extract of roots from Arctium lappa L. accelerates the healing of acetic acid-induced gastric ulcer in rats: involvement of the antioxidant system," Food and Chemical Toxicology, vol. 51, pp. 179-187, 2013.

[16] S. K. Jaiswal, C. V. Rao, B. Sharma, P. Mishra, S. Das, and M. K. Dubey, "Gastroprotective effect of standardized leaf extract from Argyreia speciosa on experimental gastric ulcers in rats," Journal of Ethnopharmacology, vol. 137, no. 1, pp. 341-344, 2011.

[17] A. A. El-Fakhry, M. A. El-Daker, R. I. Badr et al., "Association of the CagA gene positive Helicobacter pylori and tissue levels of interleukin-17 and interleukin-8 in gastric ulcer patients," The Egyptian Journal of Immunology, vol. 19, no. 1, pp. 5162, 2012.

[18] Y. W. Yin, A. M. Hu, Q. Q. Sun et al., "Association between interleukin-8 gene -251 T/A polymorphism and the risk of peptic ulcer disease: a meta-analysis," Human Immunology, vol. 74, no. 1, pp. 125-130, 2013.

[19] S. Okabe, J. L. A. Roth, and C. J. Pfeiffer, “A method for experimental, penetrating gastric and duodenal ulcers in rats. Observations on normal healing," The American Journal of Digestive Diseases, vol. 16, no. 3, pp. 277-284, 1971.

[20] K. Takagi, S. Okabe, and R. Saziki, "A new method for the production of chronic gastric ulcer in rats and the effect of several drugs on its healing," Japanese Journal of Pharmacology, vol. 19, no. 3, pp. 418-426, 1969.

[21] S. Okabe and K. Amagase, "An overview of acetic acid ulcer models - the history and state of the art of peptic ulcer research," Biological \& Pharmaceutical Bulletin, vol. 28, no. 8, pp. 1321-1341, 2005. 
[22] A. Tarnawski, J. Stachura, W. J. Krause, T. G. Douglass, and H. Gergely, "Quality of gastric ulcer healing: a new, emerging concept," Journal of Clinical Gastroenterology, vol. 13, Supplement 1, pp. S42-S47, 1991.

[23] A. S. Tarnawski, "Cellular and molecular mechanisms of gastrointestinal ulcer healing," Digestive Diseases and Sciences, vol. 50, Supplement 1, pp. S24-S33, 2005.

[24] M. Arun and V. V. Asha, "Gastroprotective effect of Dodonaea viscosa on various experimental ulcer models," Journal of Ethnopharmacology, vol. 118, no. 3, pp. 460-465, 2008.

[25] A. Alkofahi and A. H. Atta, "Pharmacological screening of the anti-ulcerogenic effects of some Jordanian medicinal plants in rats," Journal of Ethnopharmacology, vol. 67, no. 3, pp. 341345, 1999.

[26] S. Khennouf, H. Benabdallah, K. Gharzouli et al., "Effect of tannins from Quercus suber and Quercus coccifera leaves on ethanol-induced gastric lesions in mice," Journal of Agricultural and Food Chemistry, vol. 51, no. 5, pp. 1469-1473, 2003.

[27] S. Bhattacharya, S. R. Chaudhuri, S. Chattopadhyay, and S. K. Bandyopadhyay, "Healing properties of some Indian medicinal plants against indomethacin-induced gastric ulceration of rats," Journal of Clinical Biochemistry and Nutrition, vol. 41, no. 2, pp. 106-114, 2007.

[28] B. Q. Li, T. Fu, W. H. Gong et al., "The flavonoid baicalin exhibits anti-inflammatory activity by binding to chemokines," Immunopharmacology, vol. 49, no. 3, pp. 295-306, 2000.

[29] J. Wu, D. Hu, and K. X. Wang, "Study of Scutellaria baicalensis and Baicalin against antimicrobial susceptibility of Helicobacter pylori strains in vitro," Zhong yao cai $=$ Zhongyaocai $=$ Jour nal of Chinese Medicinal Materials, vol. 31, no. 5, pp. 707-710, 2008.

[30] A. M. Y. Lin, Y. H. Ping, G. F. Chang et al., "Neuroprotective effect of oral S/B remedy (Scutellaria baicalensis Georgi and Bupleurum scorzonerifolfium Willd) on iron-induced neurodegeneration in the nigrostriatal dopaminergic system of rat brain," Journal of Ethnopharmacology, vol. 134, no. 3, pp. 884-891, 2011.

[31] S. Y. Yoon, I. C. dela Pena, C. Y. Shin et al., "Convulsionrelated activities of Scutellaria flavones are related to the 5,7dihydroxyl structures," European Journal of Pharmacology, vol. 659, no. 2-3, pp. 155-160, 2011.

[32] L. Chen, J. Dou, Z. Su et al., "Synergistic activity of baicalein with ribavirin against influenza $A(\mathrm{H} 1 \mathrm{~N} 1)$ virus infections in cell culture and in mice," Antiviral Research, vol. 91, no. 3, pp. 314-320, 2011.

[33] M. Li-Weber, "New therapeutic aspects of flavones: the anticancer properties of Scutellaria and its main active constituents wogonin, baicalein and baicalin," Cancer Treatment Reviews, vol. 35, no. 1, pp. 57-68, 2009.

[34] D. E. Shieh, L. T. Liu, and C. C. Lin, "Antioxidant and free radical scavenging effects of baicalein, baicalin and wogonin," Anticancer Research, vol. 20, no. 5A, pp. 2861-2865, 2000.

[35] B. Bandyopadhyay and S. K. Bandyopadhyay, "Protective effect of zinc gluconate on chemically induced gastric ulcer," The Indian Journal of Medical Research, vol. 106, pp. 27-32, 1997.

[36] S. S. Poulsen, "On the role of epidermal growth factor in the defence of the gastroduodenal mucosa," Scandinavian Journal of Gastroenterology, vol. 128, pp. 20-23, 1987.
[37] S. Kwiecień, T. Brzozowski, P. C. H. Konturek, and S. J. Konturek, "The role of reactive oxygen species in action of nitric oxide-donors on stress-induced gastric mucosal lesions," Journal of Physiology and Pharmacology, vol. 53, 4 Part 2, pp. 761-773, 2002.

[38] I. Chattopadhyay, U. Bandyopadhyay, K. Biswas, P. Maity, and R. K. Banerjee, "Indomethacin inactivates gastric peroxidase to induce reactive-oxygen-mediated gastric mucosal injury and curcumin protects it by preventing peroxidase inactivation and scavenging reactive oxygen," Free Radical Biology \& Medicine, vol. 40, no. 8, pp. 1397-1408, 2006.

[39] M. Maes, P. Ruckoanich, Y. S. Chang, N. Mahanonda, and M. Berk, "Multiple aberrations in shared inflammatory and oxidative \& nitrosative stress (IO\&NS) pathways explain the co-association of depression and cardiovascular disorder (CVD), and the increased risk for CVD and due mortality in depressed patients," Progress in Neuro-Psychopharmacology and Biological Psychiatry, vol. 35, no. 3, pp. 769-783, 2011. 


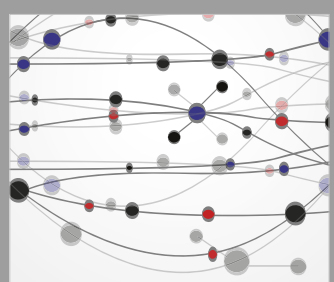

The Scientific World Journal
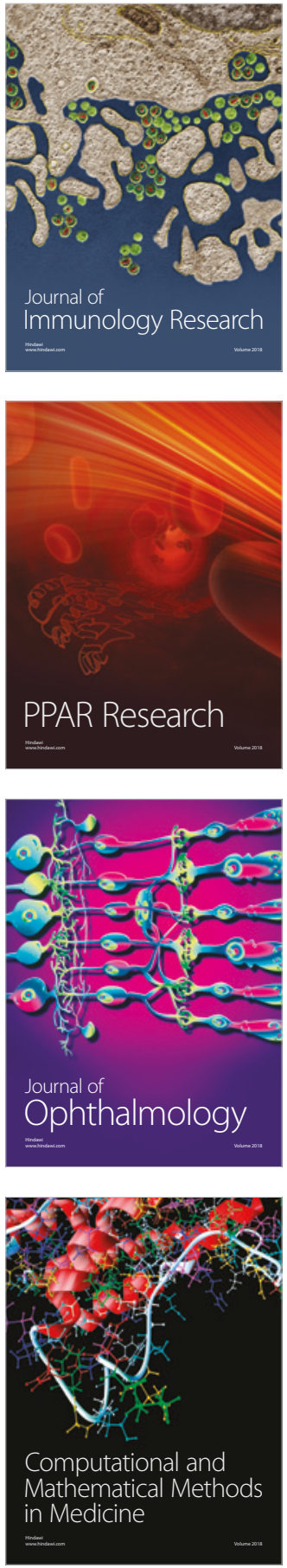

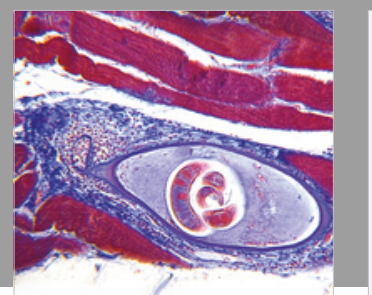

Gastroenterology Research and Practice

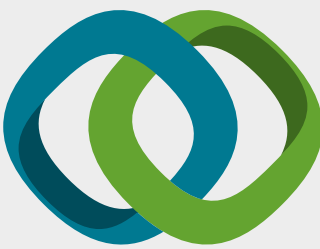

\section{Hindawi}

Submit your manuscripts at

www.hindawi.com
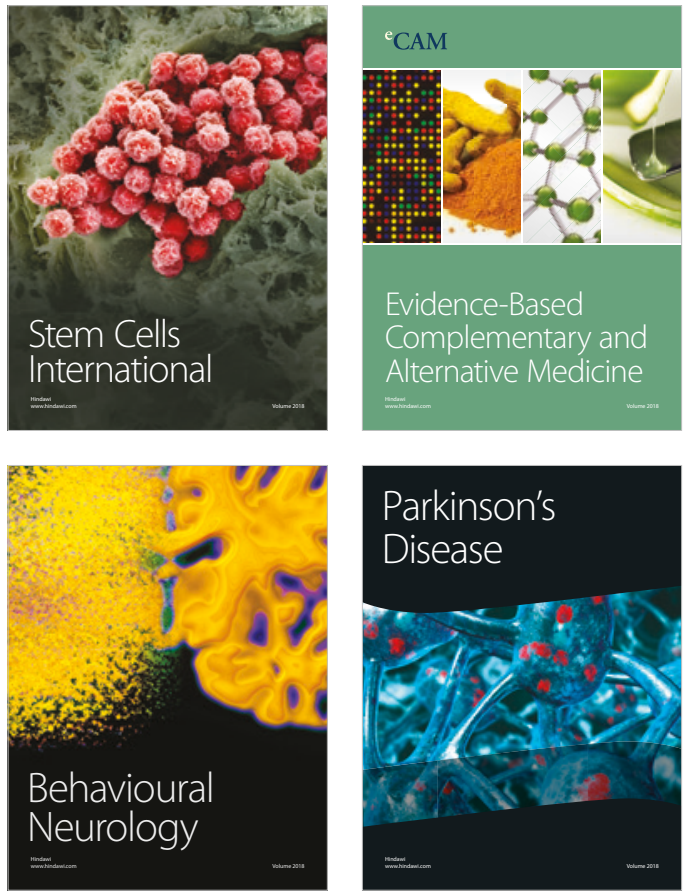

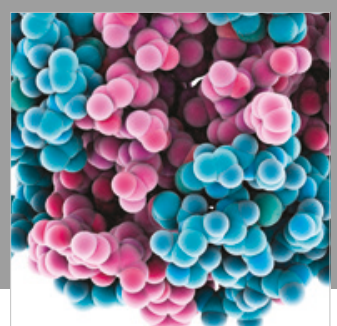

ournal of

Diabetes Research

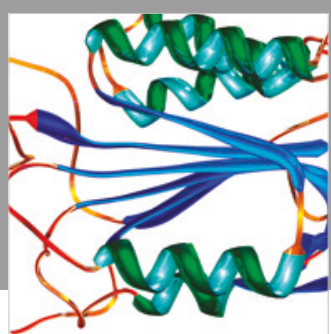

Disease Markers
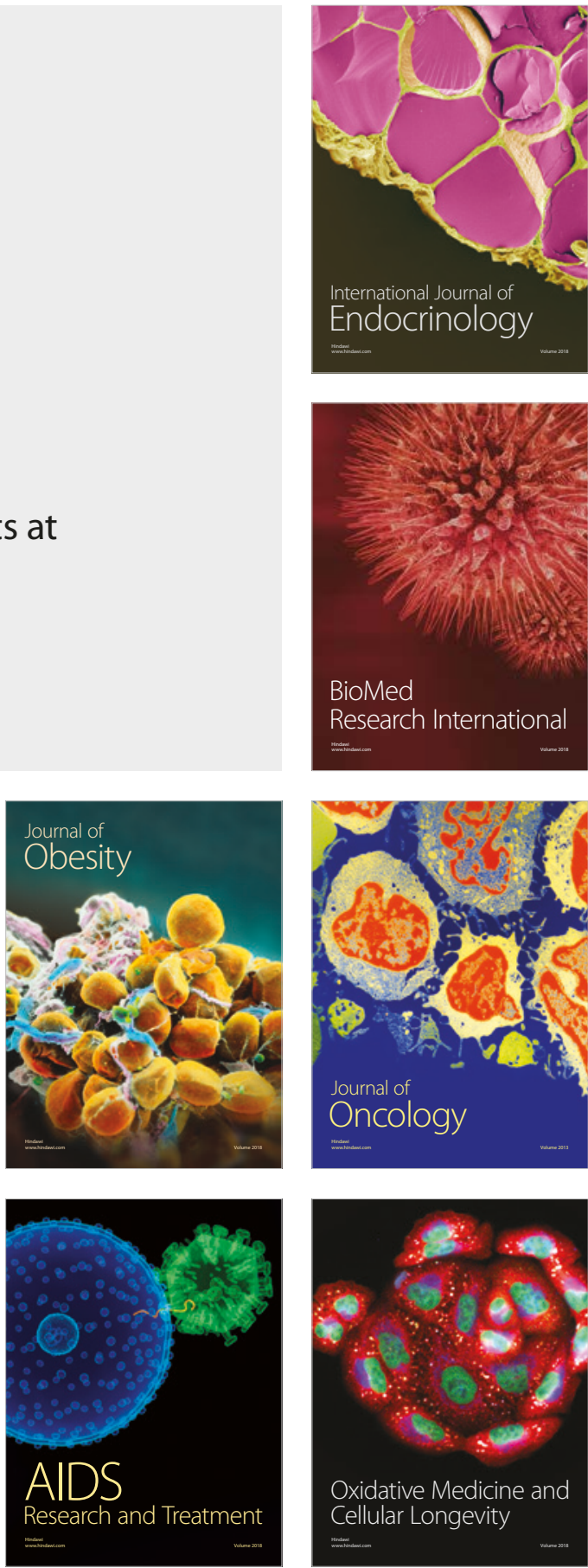